\title{
Research Paper: The Effects of 12 Weeks of Systematic and Functional Corrective Exercises on Body Posture of Students Suffering From Pronation Distortion Syndrome
}

\author{
Ali Golchini ${ }^{1}\left(\mathbb{D}\right.$, Nader Rahnama $^{1^{*}}$ (D)
}

1. Department of Sport Pathology and Corrective Exercises, Faculty of Sports Sciences, University of Isfahan, Isfahan, Iran

\begin{tabular}{|c|c|}
\hline $\begin{array}{l}\text { Use your device to scan } \\
\text { and read the article online }\end{array}$ & \\
\hline aprita: & $\begin{array}{l}\text { Posture of Students Suffering From Pronation Distortion Syndrome. Iranian Rehabilitation Journal. 2020; 18(2):181-192. http:// } \\
\text { dx.doi.org/10.32598/irj.18.2.937.1 }\end{array}$ \\
\hline 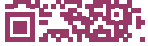 & doi'http://dx.doi.org/10.32598/irj.18.2.937.1 \\
\hline
\end{tabular}

Article info:

Received: 31 Jul 2019

Accepted: 01 Dec 2019

Available Online: 01 Jun 2020

Keywords:

Pronation, Exercises, Posture, Function

\section{A B STRACT}

Objectives: Pronation distortion syndrome is one of the common physical deformities, that causes distortions in the skeletal structures of the feet. The current study aimed to determine the effects of 12 weeks of systematic and functional corrective exercises on the body posture of students with pronation distortion syndrome.

Methods: In this quasi-experimental study, 30 volunteers suffering from pronation distortion syndrome were selected. Then, they were randomly divided into two 15 -member groups, i.e. the experimental and the control groups. The experimental group practiced systematic and functional corrective exercises for 12 weeks (three sessions a week, each lasting an hour), while the control group did not receive any exercises. Before and after the exercises, the students were evaluated using the Functional Movement Screen (FMS) screening test as well as body posture tests, including flat feet, pronation angle of ankle joint, knock-knee (bow-leggedness or genu valgum), and lumbar lordosis (swayback). The obtained data were analyzed using the dependent and independent t-tests $(\mathrm{P}<0.05)$.

Results: After 12 weeks of systematic and functional corrective exercises, the experimental group showed significant improvement in FMS and body posture $(\mathrm{P}=0.001)$. However, no significant difference was observed in the control group $(\mathrm{P}<0.05)$. In general, the body posture of the experimental group was significantly better than the control group $(\mathrm{P}=0.001)$.

Discussion: Based on the findings of the current study, systematic and functional corrective exercises improve the body posture of students suffering from pronation distortion syndrome Therefore, these exercises are recommended for such students. 


\section{Highlights}

- The use of FMS for measuring the likelihood of injury of students with pronation distortion syndrome.

- Systematic and functional corrective exercises improve the body posture of students with pronation deviation syndrome.

- Systematic and functional corrective exercises reduce the likelihood of injury of students with pronation deviation syndrome.

\section{Plain Language Summary}

Pronation distortion syndrome due to excessive foot pronation includes inward rotation of the tibia, internal rotation of the thighs associated with flat feet, genu valgum (knock-knee), and increased lordosis in case of hyperpronation. In this study, corrective exercises were used to improve body posture. The results of this study showed that systematic and functional corrective exercises can improve body posture. Therefore, this method can be used for people with pronation distortion syndrome and for reducing the likelihood of injury.

\section{Introduction}

ronation distortion syndrome is a common

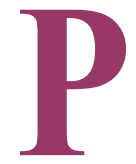
postural distortion of the lower extremity, involving the anterior part of the leg. It may cause pain in the leg and disturbances in the tarsal part, in addition to distal and proximal parts [1]. In this deformity, the head of the talus and navicular bones are rotated inward and downward, and the body's center of gravity shifts inward, resulting in flat feet. It is also associated with a bunion and increased pressure on the medial parts of the first and second metatarsophalangeal joints.

The characteristics of pronation distortion syndrome due to excessive foot pronation include inward rotation of the tibia, internal rotation of the thighs associated with flat feet, genu valgum (knock-knee), and increased lordosis in case of hyperpronation. In this deformity, peroneal muscle, gastrocnemius muscle, hamstrings, soleus muscle, iliotibial band, adductors, and psoas muscle are functionally tightened, while posterior and anterior tibialis, gluteus medius, gluteus maximus, vastus medialis, and hip external rotators are inhibited. Also, potential joint dysfunctions include the first metatarsophalangeal, subtalar, sacroiliac, talocrural, and lumbar facet joints [1, 2].

Normally, individuals with pronation distortion syndrome show predictable patterns of injury, including tendon injury, plantar fasciitis [3], posterior tibialis tendonitis [4], ankle sprain or instability [5], patellar tendinopathy and patellofemoral pain syndrome [6], anterior cruciate ligament injury, posterior tibial tendon dysfunc- tion, and low-back pain $[1,2]$. Moreover, these people are at a greater risk of foot pain, knee pain, stress fractures, poor sports performance, and imbalance [7]. Possible movement disorders include restricted dorsiflexion of the thoracohedral joint, and weakness of supinators, ankles, intrinsic muscles of the leg, and external rotators of the hip [8]. Therefore, people with pronation distortion syndrome experience a physical deformities condition.

The kinematics of proximal joints may influence the kinematics of the distal joints [9]. Hyperpronation of the foot affects sensory inputs by altering joint mobility, contact surface area, changes in ligament status, and development of ligamentous laxity, or through secondary pathways by inducing changes in muscle structures to maintain a solid and reliable level of reliance, ultimately leading to distortion in the posture of the body. The hyperpronation of the foot is also accompanied by various degrees of ligamentous laxity [10], which may cause changes in the soft tissues around the joints, including ligaments, muscles, and tendons. These soft tissues usually contain several mechanical receptors and sensory neurons (muscular spindles, Golgi tendon organs, and joint receptors) [11].

Khayam Bashi et al., (2012) believed that strengthening hip abductors and hip external rotator muscles can lead to kinematic changes in the distal region of lower extremities [12]. After administering six weeks of strength training using the closed kinetic chain of hip abductors and hip external rotators, Synder et al., (2009) found out that the rear foot angle of the participants decreased, but this reduction was not significant [13]. Dadashpour et al., (2014) argued 
that body organs are like the connected rings of a chain where each component influences the others. Therefore, by performing closed kinetic chain exercises under loads and by increasing the strength of the muscles proximal to the lower extremities, one can correct the hyperpronation of the foot in the distal lower extremities [14].

Farokhmanesh et al., (2012) reported that hyperpronation of the foot in the closed kinematic chain would result in the internal rotation of the tibia, which might affect the performance of the knee joint, followed by the internal rotation of the femur and frontal pelvic tilt. With the increasing pelvic tilt, lumbar vertebrae shift forward, increasing the lumbar arch. Therefore, the distance between the line of gravity and the kinetic axis of the joint would increase, resulting in an extraneous torque increase relative to the optimal natural state [15].

Many attempts have been made to correct pronation of the foot via directly targeting the foot using conventional interventions, such as orthoses [16], braces [17], ankle exercises [18], therapeutic footwear, and exercises for hip joint strength [13]. On the other hand, inconsistent findings have been reported regarding the efficacy of corrective exercises in foot pronation and the effect of flat feet on other factors related to physical fitness. Some studies have reported that people with flat or claw feet have weaker postural control in comparison with those with normal feet [19]. However, some studies have not confirmed such a relationship [20]. Also, several studies show that the corrective exercise program has no significant effects on the improvement of flat feet [20].

According to the literature, no study has yet demonstrated the effectiveness of corrective exercises with a systematic approach in the improvement of disorders in pronation distortion syndrome, and the proposed treatment techniques are contradictory. These exercises may also reduce the cost of treatment in the future and decrease the time spent on rehabilitation and treatment. Therefore, the purpose of this study was to determine the effect of corrective exercises with a systematic and functional approach on the body posture of patients with pronation distortion syndrome.

\section{Methods}

In this quasi-experimental study with a pre-test/post-test and control group design, we evaluated the effects of corrective exercises on the body posture and functional movement of students with pronation distortion syndrome.

\section{Study sample}

The statistical population included male students aged 1016 years, who were selected based on a general assessment using the New York test and a coherent assessment according to the inclusion and exclusion criteria out of 1836 students via a purposive sampling method. The study sample comprised 30 male students with pronation distortion syndrome, who were evaluated in the Corrective Exercise Training Center Clinic (district one). The subjects were purposefully selected and randomly assigned into experimental (Mean $\pm \mathrm{SD}$ age $=12.66 \pm 1.72$ years; Mean \pm SD height $=165.3 \pm 6.58 \mathrm{~cm}$; Mean \pm SD weight $=67.29 \pm 5.72 \mathrm{~kg}$; Mean \pm SD body mass in$\mathrm{dex}=24.55 \pm 1.63 \mathrm{~kg} / \mathrm{m}^{2}$; Mean \pm SD leg length $\left.=81.6 \pm 4.22 \mathrm{~cm}\right)$ and control (Mean \pm SD age $=12.66 \pm 1.83$ years; Mean \pm SD height $=166.4 \pm 9.5 \mathrm{~cm} ; \quad$ Mean $\pm \mathrm{SD}$ weight $=68.9 \pm 9.9 \mathrm{~kg}$; Mean \pm SD body mass index $=24.71 \pm 5.21 \mathrm{~kg} / \mathrm{m}^{2}$; Mean $\pm \mathrm{SD}$ length $=82.4 \pm 6.88 \mathrm{~cm}$ ) groups.

The experimental and control groups were matched in terms of height, weight, age, length of lower extremity, body mass index, pronation status, and supporting leg. After coordinating with the orthopedist, corrective exercise specialists were assessed from April 2018 until June 2018. Then, study information was presented to the selected samples and their parents about pronation deviation syndrome, study objectives, research methods, and requirements for corrective exercises. If they were willing to participate in the study, they would sign a written consent form. After signing the consent form and considering the research limitations, they were divided into two groups.

\section{Exclusion and inclusion criteria}

The inclusion criteria were as follows: diagnosis of pronation deviation syndrome in both feet, based on the corrective exercise specialist's opinion; detection of flexible flat feet without pain, evaluated by heel-rise test, navicular drop more than $10 \mathrm{~mm}$, and grade 2 flat feet, [7, 21-25]; age range of 10-16 years; having a normal vision or corrected vision using spectacles or contact lenses; absence of other acute or chronic diseases preventing from exercise; physician's agreement with corrective exercises; no history of injury or surgery on the ankle, knee, thighs, hip, or back; and completing the informed consent form and an individual health questionnaire [26].

On the other hand, the exclusion criteria were as follows: the presence of pain or emergence of pain during the study; not completing the pre-test or post-test; and inconsistent participation in exercise sessions (absence from two consecutive sessions or three sessions during the course) [26]. 
Systematic and functional corrective exercise training program

The experimental group participated in a systematic and functional corrective exercise program for three months, while the control group continued their routine activity. The corrective training program consisted of two sections: I. educational (training of daily physical activities, all of which were completely explained in a 2-h theory session); and II. exercise. The exercise section consisted of 21 exercises:

A. Restraint exercise or self-release: involving the gastrocnemius muscle, soleus muscle, fibula, knee compressor muscles, adductors of the thighs, the short head of the biceps femoris, and iliotibial band for 30 seconds, using a foam roller;

B. Static stretching drills: involving the soleus and gastrocnemius muscles on an inclined plane, tensor fasciae latae muscle, short head of the biceps femoris, and iliopsoas muscle;

C. Resistance exercises: strengthening the eccentric muscles of the feet including dorsiflexion and knee inversion, adduction, and extension, external rotation of the hip joint with TheraBand exercise band, and strengthening the intrinsic muscles of the foot;

D. Integrative exercise: including the star balance test on all planes; wobble board and stair climbing exercises on all planes, TRX exercises (total resistance exercises), and gym ball exercise.

In all exercises, the principle of overload was observed. The corrective exercises were based on multiple scientific resources, as presented in Table $1[2,8,27]$. The experimental group participated in the training program one day after the pre-test (three sessions per week for three months). The corrective exercises for the experimental group consisted of 36 sixty-minute sessions (initial warm-up: 10 minutes, restraint exercise for $10 \mathrm{~min}$ utes, stretching, strength, and integrative exercises for 35 minutes, and cool-down for 5 minutes) [2, 8].

\section{Variable evaluation}

Before and after the corrective exercise program, the selected variables in both groups were evaluated and measured. The tests included the A: Functional Movement Screen (FMS) test; and B: body posture status test.

\section{A. Functional Movement Screen (FMS) test}

The Functional Movement Screen (FMS) test has been used for devising functional evaluation programs before participating in athletic activities [28]. This set of tests was designed using 7 movement patterns for the simultaneous evaluation of mobility and stability. Because of the short administration timeframe of 5 to 10 minutes, it can be easily used by coaches and evaluators. This set of tests include the deep squat, hurdle step, inline lunge, shoulder mobility, active straight-leg raise, trunk stability push-up, and rotary stability [29].

In previous studies, medium to good intra-rater and inter-rater reliabilities have been reported for this set of tests [30]. Besides, this test has been reported as a sufficiently reliable test for predicting physical injuries in a way that scores lower than 14 indicates that the individual is four times more likely to be injured [31]. The maximum score for this test is 21 . The scoring method is as follows: correct performance of the movement without compensations: 3 points; performing the movement with compensations: 2 points; failure to perform the movement without compensations: 1 point; and having pain during any part of the movement: 0 points $[29,32]$

\section{B. Body Posture Status tests}

\section{Navicular drop}

The navicular drop was evaluated using the method described by Brody [7]. The reliability coefficient of this test was reported as $\mathrm{r}=85 \%$ by Muller et al., $\mathrm{r}=80 \%$ by Walker et al., $r=70 \%$ by Hurtle et al., and $r=76 \%$ by Evans et al., [33]. During this test, the subject sits on a chair in a way that the feet are in a completely weightless state. The examiner will put the subject's feet in neutral rotation, i.e. in its natural state; then, by touching the inside of the ankle and applying simultaneous internal and external rotations, the prominence of the top of the navicular bone is detected. Then, the distance between the prominence of the top of the navicular bone and the floor is measured and recorded on a piece of paper.

Then, the subject is asked to stand up and under his or her weight, the distance between the prominence of the top of the navicular bone and the floor is measured again. Finally, by measuring the difference between the two measurements, the extent of the navicular bone drop is determined. The extent of navicular drop is measured three times for each subject, and the average is recorded for the analysis. Subjects with a navicular drop of more than $10 \mathrm{~mm}$ are considered subjects with flat feet and entered into the 
Table 1. Summary of systematic and functional corrective exercise program

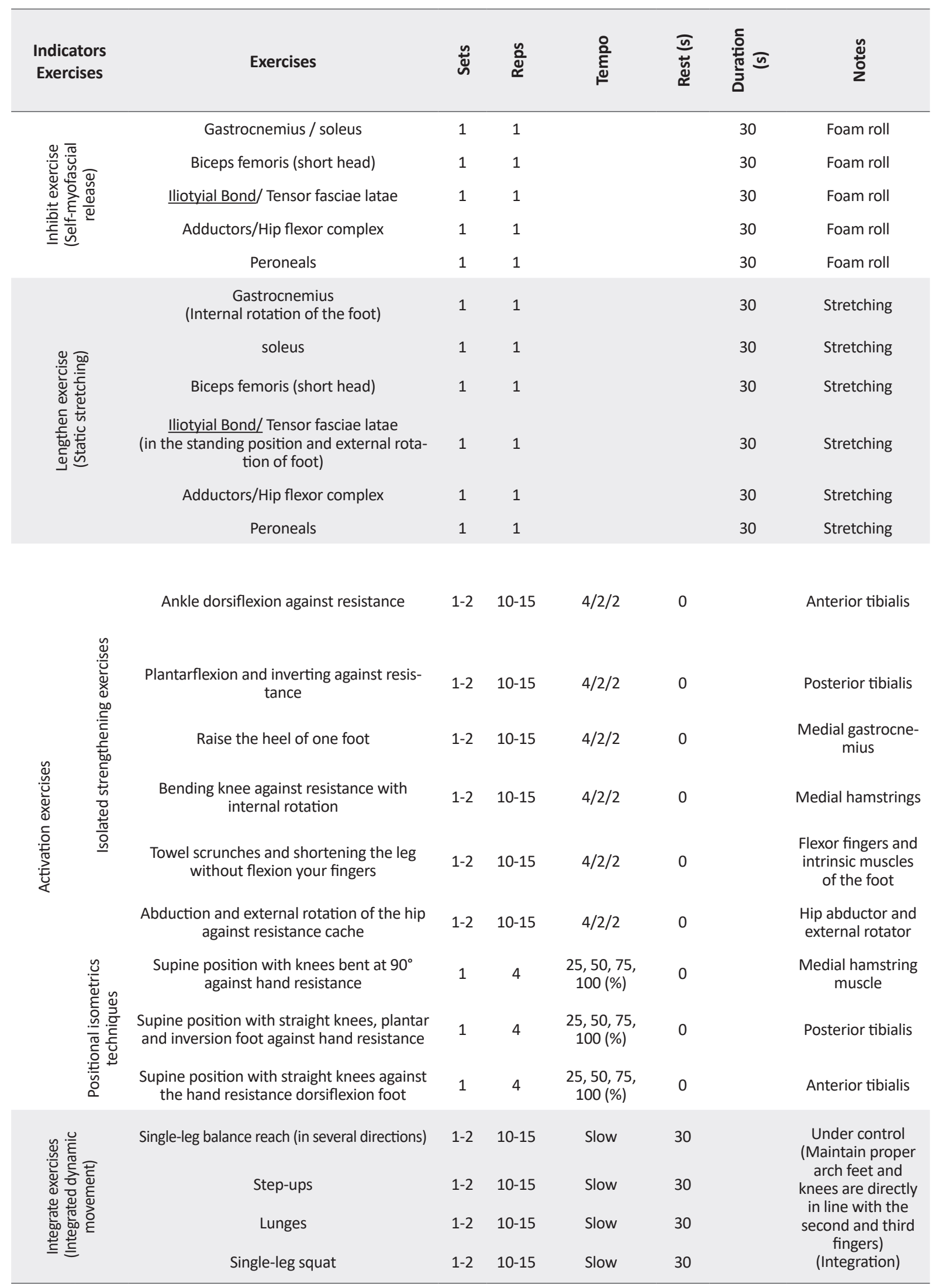

Iranian Rehabilitation Journal 
study [7]. In this study, since the flexible flatfoot grade 2 is considered a criterion for entering the study, the footprint test, i.e. evaluating the bottom of the feet on a mirror box, was used to select the subjects with flexible flatfoot grade 2 based on the Denise A method in which the support of the central section and top of the foot are equal [21].

Pronation of the ankle (the valgus angle of the ankle)

This factor is determined by measuring the hindfoot valgus angle (the angle behind the ankle). This procedure is done by drawing the midline of the leg in the bottom third and the midline of the heel of the subject while the subject is lying on his or her abdomen. Then, the subject is asked to stand up and when the feet are under the weight of the individual, the angle between these two lines is measured using a goniometer. The natural angle is 180 and an angle more than 9 degrees is considered as hyperpronation [16]. In an experimental study on 15 participants, the reliability of measuring the valgus angle (ICC $=0.69$ ) was found as good [14].

\section{Knock-knee (Bow-leggedness or genu valgum)}

To measure the knee valgus while standing, the inside distance between the two ankles is measured using a caliper. To do so, the subject is asked to take off his or her shoes and socks and to stand on a flat surface in a comfortable and direct stance while his her knees and thighs are visible for the evaluator and his or her feet are completely parallel to each other. Under this condition, the subject does not have any unnatural contraction or tension in his or her thigh muscles. This is done in a way that the individual's intercondylar and intermalleolar points are the closest to each other in their natural state and the hips and thighs are completely extended. To measure the distance, the intercondylar and intermalleolar points are identified. To find these points, in the internal section of the lower end of the thigh and the upper end of the knee joint, the largest and smoothest knob protruding backward is selected as the internal condyles of the knee and the protruding parts in the internal area of the lower end of the tibia and the upper section of the ankle joint are considered as the internal ankles of the feet. Then, these distances are measured using a caliper.

The measurements are performed three times, and the average is calculated [22]. A distance lower than $2.5 \mathrm{~cm}$ is considered grade one, a distance between 2.5 to $5 \mathrm{~cm}$ grade two, a distance between 5 and $7.5 \mathrm{~cm}$ grade three, and a distance of more than $7.5 \mathrm{~cm}$ grade 4 and acute [34]. To evaluate the dynamic valgus of the knee during a lunge, the landing error scoring system (LESS) is used. It is a clinical tool for dynamic movement used for identifying unfavorable patterns during landing after lunge. This test evaluates the landing technique based on $9 \mathrm{im}$ ages of the landing and using 13 yes/no questions. The higher LESS scores indicate higher errors during landing, indicating higher vulnerability to injuries [2]

This system has a high application capability and it can clinically evaluate the risky landing mechanics. The intra-rater and inter-rater reliability values of this test have been reported as good and excellent, respectively [25]. Moreover, they have shown its predicting capability for identifying individuals with a high risk of injury [35]. Besides, LESS can effectively show the changes in the landing technique caused by an intervention program [36].

To perform this test, the corrective exercise expert first shows the correct way of performing the motion and then

Table 2. The scoring method for the adjusted landing error scoring system

\begin{tabular}{|c|c|}
\hline Observing Frontal View & Observing Lateral View \\
\hline $\begin{array}{l}\text { Standing width or two feet distance: } \\
\text { Normal (0), wide (1), narrow (1) }\end{array}$ & $\begin{array}{l}\text { Initial landing of the feet: } \\
\text { Toe-heel (0), heel-toe (1), flatfeet (1) }\end{array}$ \\
\hline $\begin{array}{l}\text { Maximum rotation of the foot: } \\
\text { Normal (0), medium external rotation (1), mild internal rotation (1) }\end{array}$ & $\begin{array}{l}\text { Movement of the knee flexion: } \\
\text { Large (0), medium (1), low (2) }\end{array}$ \\
\hline $\begin{array}{l}\text { Concurrent initial contact with the surface: } \\
\text { Concurrent (0), non-concurrent (1) }\end{array}$ & $\begin{array}{l}\text { Movement of trunk flexion: } \\
\text { Large (0), medium (1), low (2) }\end{array}$ \\
\hline $\begin{array}{l}\text { Maximum knee valgus angle: } \\
\text { Normal (0), small (1), large (2) }\end{array}$ & $\begin{array}{l}\text { General movement in sagittal screen: } \\
\text { Large (0), medium (1), low (2) }\end{array}$ \\
\hline $\begin{array}{l}\text { Lateral flexion of the trunk: } \\
\text { Not observed (0), low to medium (1) }\end{array}$ & $\begin{array}{l}\text { Total test score: } \\
\text { Excellent (0), medium (1), poor (2) }\end{array}$ \\
\hline
\end{tabular}

A score higher than 6 means the poor result, indicating the individual is vulnerable to large valgus; a score between 5 and 6 indicates medium valgus; a score between 4 and 5 indicates good result with low valgus; and a score of means excellent result with normal valgus. 
Table 3. Functional Movement Screen (FMS) test and variables of pronation distortion syndrome

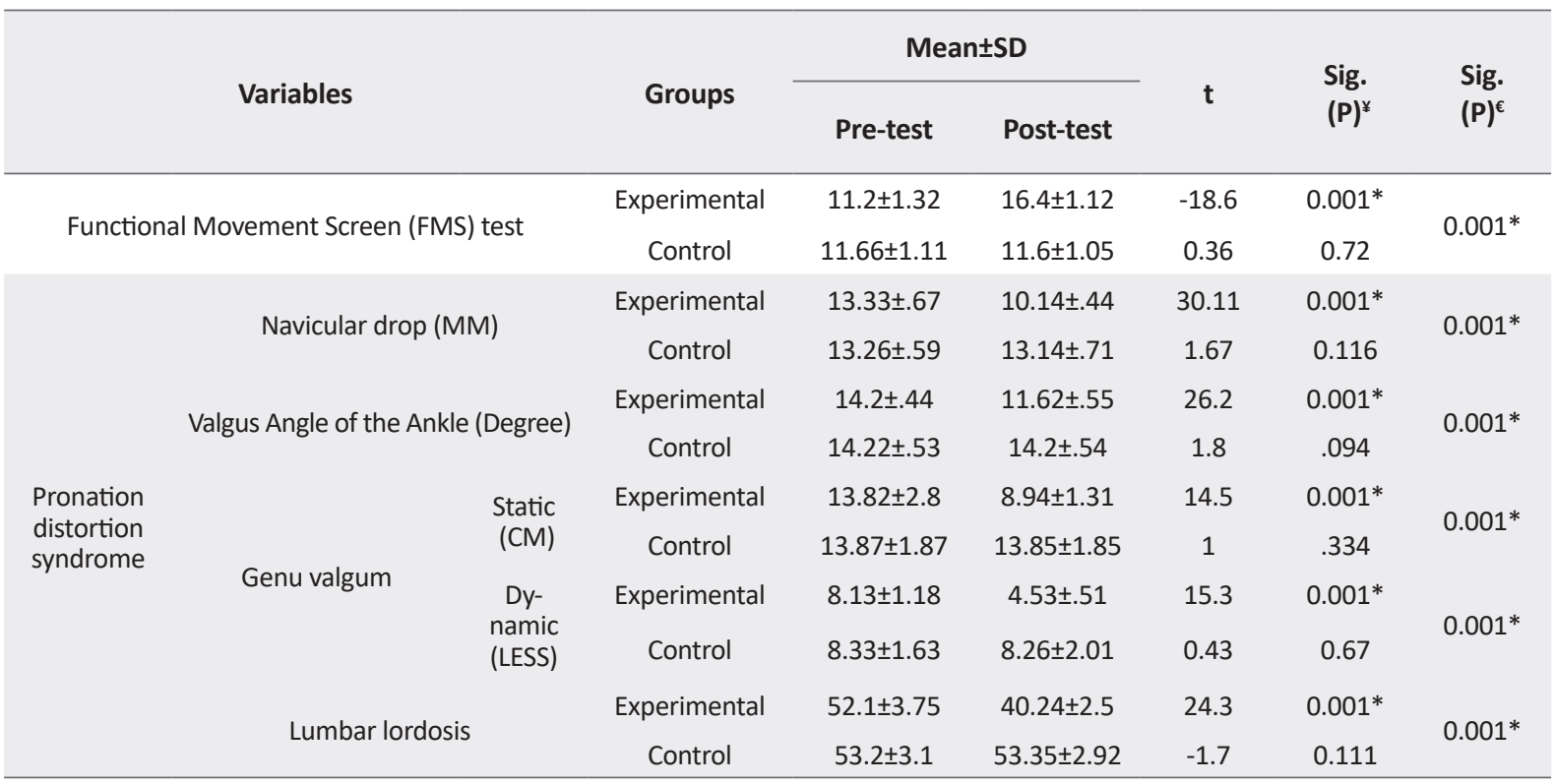

Пranian Rehabilitation \ournal

$P^{¥}:$ Value indicates within-group differences (the paired-samples t-test). $P^{\epsilon}$ : Value indicates between-group differences (independent samples t-test); ${ }^{*}$ Indicates a significant difference $(\mathrm{P}<0.05)$.

video cameras (Canon PC1818 cameras made in Japan) are ideally placed with a distance of $3 \mathrm{~m}$ in front and $3 \mathrm{~m}$ on the right side of the landing point. Then, the subjects start exercise. In the pre-test session, the subjects jumped from a $30-\mathrm{cm}$ platform landing in front of the platform at a distance of approximately $50 \%$ of their height. Immediately after that, they performed a maximum vertical jump.

During the training for the test, the individuals were advised to jump up immediately after landing from the platform. During the test, the subjects do not receive any feedback or training unless they were doing the test wrong. After training the subjects, they were allowed to have two drill jumps to learn the exercise. Then, the subjects performed three accurate jumps. If a subject failed to reach the predetermined horizontal distance or if the subject did not perform the maximum vertical jump after landing, that round would be eliminated and the jump-landing maneuver would be repeated once more [25]. Ultimately, the videos were evaluated from the frontal and lateral views and the main compensations were considered as follows.

1. Placement of the feet: the state of the feet at the moment of contact, the fingers have less than 30 degrees of external rotation, $\mathrm{no}=0$, and yes $=1$;

2. State of the knee: a. knee valgus at the moment of contact: placement of the kneed above the middle por- tion of the leg, yes $=0$ and no $=1 ; b$. movement of the knee valgus: knee inside the big toe, no $=0$, and yes $=1$.

Using this method, the potential lack of muscular balance can be diagnosed and considered in the corrective exercise program [2]. Table 2 presents the scoring scheme for the adjusted LESS test.

\section{Lumbar lordosis}

To evaluate this factor, a Kidoz flexible ruler was used. A study reported the degree of ICC equal to 0.82 by using a flexible ruler for measuring the lumbar arch of individuals with lumbar pain [24]. To measure the degree of lumbar lordosis, we have to identify T2, T12, and S2 bone points first by touching and mark them using a marker. Then, the subjects were asked to let their hands fall beside their body with a $15-\mathrm{cm}$ distance between the two feet, while standing with bare feet. They were asked to distribute their weight equally between the two legs and look at a constant point on the opposite wall and stand comfortably. Then, a special fixation tool was placed on the sternum and pelvis of the subject to prevent the subject from swaying in the sagittal screen during the measurements. The flexible ruler was placed between T12 and S2 on the shock process of the vertebrae; an equal pressure was applied to the ruler with no space between the skin and the ruler so that the ruler curved over the lumbar arch [23]. 
It is worth mentioning that about $3 \mathrm{~cm}$ from the top of the ruler was released and then the selected points were marked on the ruler. Then, the evaluator, without changing the obtained arch, used his or her two hands to grab both ends of the flexible ruler and slowly and without any change put the ruler on the special checkered paper. Then, the examiner marked the points on the paper and draws the curve of the ruler using a pencil on the paper as well. Next, the ruler was removed and on the paper, a direct line was drawn from $\mathrm{T} 12$ to $\mathrm{S} 2$ points. To measure the lumbar lordosis, similar to the Yodas Method, the thorn-like T12 process is selected as the starting point for the lumbar curve and the S2 process is considered as the final point of the curve [37].

The distance between these two points is considered $\mathrm{L}$ and the vertical height from this line to the center of the arch (the deepest point of the arch) is considered $\mathrm{H}$. Then, to measure the lumbar angle, the following formula is used. Using this method, the average lordosis angle in healthy individuals is shown to be up to 50.9 degrees and for the age group of younger than 14 years, the angle is up to 34.45 degrees, while for the age group of 15-25 years, the angle up to 32.20 degrees is considered normal [38].

$$
\theta=4\left[\arctan \frac{2 H}{L}\right]
$$

All these tests are performed in the same session so that the students do not feel any discomfort. The moods of the students during the tests were monitored and after each test, sufficient rest time was considered to avoid fatigue or injury.

\section{Statistical analysis}

In this study, variables are presented using descriptive statistics, and data analysis was performed using inferential statistics. Descriptive tests, including mean and standard deviation, were used to describe the data. Among the inferential tests, the Kolmogorov-Smirnov test was initially used to verify the normal distribution of data. Next, the independent t-test was used to compare the mean of groups and to examine the effect of the independent variable on dependent variables. SPSS V. 22 was used to analyze the data. The significance level in this study was set at 0.05 with $95 \%$ confidence interval.

\section{Results}

\section{A. Functional Movement Screen (FMS) test}

Table 3 presents the data related to the students' FMS. The experimental group showed a significant improve- ment in physical fitness after 12 weeks of systematic and functional corrective exercises (FMS test) $(\mathrm{P}=0.001)$. However, no significant difference was observed in the control group $(\mathrm{P}>0.05)$. Overall, there was a significant difference between the experimental and control groups regarding the results of the FMS test $(\mathrm{P}=0.001, \mathrm{t}=12.07)$. In other words, the physical fitness of the experimental group was superior to that of the control group.

\section{B. Body posture status}

Table 3 also presents the data related to the students' body posture status. In the experimental group, after 12 weeks of systematic and functional corrective exercises, body posture (navicular drop test, hindfoot valgus angle, static and dynamic knock-knee, and lumbar lordosis) significantly improved $(\mathrm{P}=0.001)$. Nevertheless, no significant difference was observed in the control group $(\mathrm{P}>0.05)$. There was a significant difference between the experimental and control groups regarding the result of the body posture status tests $(\mathrm{P}=0.001)$. In other words, the body posture status of the experimental group was superior to that of the control group.

\section{Discussion}

The main objective of the current study was to determine the effects of systematic and functional corrective exercises on the body posture of students suffering from pronation distortion syndrome. Based on the findings of the study, the participants in the experimental group who went through the FMS test using 7 movement tests to evaluate the likelihood of injury and their body posture (using navicular drop test, hindfoot pronation angle, static and dynamic knock-knee, and lumbar lordosis) during the post-test period showed a better performance and body posture compared with the control group. Moreover, these participants are less likely to be injured in the future, which indicated the effectiveness of the systematic and functional corrective exercise program compared with the conventional method. In other words, the average difference between the scores of the post-test in the FMS was significant since it was 4.8 points.

The average difference for the scores obtained in the post-tests of body posture evaluation was significant and this difference for the navicular drop test was $3 \mathrm{~mm}$. The difference in the goniometer tests for the hindfoot valgus angle was 2.58 degrees. Also, the difference in the test for evaluating static knock-knee by measuring the internal distance between the two ankles using a caliper was $4.91 \mathrm{~cm}$, and the difference for dynamic knock-knee using the LESS was 3.73 points. 
Finally, regarding the flexible ruler test for evaluating lumbar lordosis, the difference was 13.11 degrees. Based on these results, the average scores obtained by the experimental group were better than those of the control group and the differences were significant (Table 3). It is worth mentioning that there is a difference with regard to the average scores of the above-mentioned variables between the post-test and the pre-test in the control group, but the difference was not significant.

The results are in line with the results of studies carried out by Lynn et al. [39], Daneshpour et al. [14], Sulowska et al. [40], Young-Mi Goo et al. [41], Mahdavi et al. [42], and Najafi et al. [43]. This compatibility can be explained as these studies have used corrective exercises similar to the exercises used in this study as well as the similar participants.

The results oppose with the results obtained by Synder et al., [13], Kouhi et al., [44], Ahmad Alidokht et al., [26], and Lee et al., [45]. The lack of conformity between these studies and the current study might be due to the type of the study since the current study utilizes corrective exercises while some of the above-mentioned studies were the comparative type. In the current study, corrective exercises were performed for improving body posture and increasing muscular strength. Moreover, using different exercise protocols, the characteristics of the participants (different age, gender, and populations), and different tools and evaluation instruments can be other reasons for the discrepancies in the results.

Musculoskeletal abnormalities are poor conditions caused by environmental factors, impaired motor function, and incorrect muscle and joints function [46]. If there is no proper coordination in the strength between the opposing muscles on either side of the joint, the likelihood of injury and physical anomalies increases [47]. Synergistic muscle groups have been recognized as a major contributor to joint durability, and the relative strength of these muscle groups are considered in assessing the prevention of injury and correction of physical abnormality, as well as monitoring the progression of rehabilitation and treatment by researchers and therapists [48].

By increasing the strength of the abductor muscles and the hip external rotator muscles, the internal rotation and the proximity of the thigh and lower extremity to the midline of the body may be decreased and controlled. Then this decrease is transmitted to the distal region of the lower limb (ankle) and affects it, causing the correction and reduction of the heel aversion and the distortion of the heel inward. Therefore, the abductor muscles and hip external rotator muscles play a key role in the alignment of the lower limbs, because when the distal region of the lower limb is fixed somewhere, movement in one section affects other parts of the kinetic chain, which generally leads to a decrease in pronation of the foot [49].

With regard to the issue of how the systematic and functional corrective exercise program can affect the strength of the muscles in the lower extremities, body deformities, and reduction of the likelihood of injury, we have to say that relaxation, stretching, contraction, and muscle strengthening of the central region of the body, thighs, knees, legs, ankles, and soles of the foot improve the musculoskeletal system and the coordination and balance, and increase the efficiency and functionality of the muscles and joint receptors, which increases their muscular strength, in particular, in hyperactive and controlled muscles. This process makes the lumbopelvichip joints perform better during the chain of functional movements and performing functional tests (FMS and LESS tests), so the subjects can get a better record.

Thus, the average score measured in the screening tests for functional movements increases. Moreover, the subjects will get a better body posture, which can be due to the effects of the systematic and functional corrective exercises on increasing the internal longitudinal arch of the feet and the efficiency of the arches in the bottom of the feet, the reduction of hindfoot angle, the knock-knee, and the lumbar lordosis, helping the maintenance of the correct alignment of the body, controlling the movement, and higher physical capability in individuals with pronation distortion syndrome of the foot. In other words, various parts of the body act like a chain, where each component affects the others in a way that by performing suitable corrective exercises and increasing the muscular strength of the lower limbs and the body, can correct the pronation distortion syndrome of the foot and reduce the likelihood of injury in such individuals.

\section{Conclusions}

Based on the findings of the present study, systematic and functional corrective exercises improve the body posture of students suffering from pronation distortion syndrome of the foot. Therefore, utilizing these exercises is recommended for this population. Also, systematic and functional corrective exercises (strength and integrated exercises) must become a major part of the corrective exercises program to increase muscular strength, improve body posture, and ultimately reduce the likelihood of injury in individuals suffering from the pronation distortion syndrome. 
In this study, nutrition, mental status, and mental state control of subjects were restricted. The study was also conducted for male students only. It is suggested that similar research be performed on larger samples. Also, samples of male and female students of different ages be evaluated. It is suggested that similar research be conducted on people at different times and longer duration and assess the outcomes. Similar studies can be performed to correct and treat other upper-body and midbody abnormalities such as lower-crossed syndrome, upper-crossed syndrome, and other abnormalities localized in different ages and groups.

\section{Ethical Considerations}

\section{Compliance with ethical guidelines}

The research protocol was approved by the Ethical Committee of Isfahan University (Code: IR.UI.REC.1396.037) and RCT (Code:IRCT20190824044597N1) and informed consent was provided from all participants.

\section{Funding}

The present paper was extracted from the $\mathrm{PhD}$. thesis of the first author at the Department of Pathology and Corrective exercises and Biomechanics, Faculty of Sports Sciences, Isfahan University.

\section{Authors' contributions}

All authors contributed in preparing this article.

\section{Conflict of interest}

The authors declared no conflict of interest.

\section{References}

[1] Hertling D, Kessler RM. Management of common musculoskeletal disorders: Physical therapy principles and methods. Philadelphia: Lippincott-Raven; 2006. https://books.google.com/ books?id=sB3ybDCS5rgC\&dq

[2] Clark M, Lucett S. NASM essentials of corrective exercise training. Philadelphia, PA: Lippincott Williams \& Wikins; 2011. https:// books.google.com/books?id=tZGIM2xzeSwC\&pg

[3] Irving DB, Cook JL, Menz HB. Factors associated with chronic plantar heel pain: A systematic review. Journal of Science and Medicine in Sport. 2006; 9(1-2):11-22. [DOI:10.1016/j. jsams.2006.02.004] [PMID]
[4] Moen MH, Tol JL, Weir A, Steunebrink M, De Winter TC. Medial tibial stress syndrome: A critical review. Sports Medicine. 2009; 39(7):523-46. [DOI:10.2165/00007256-200939070-00002] [PMID]

[5] Holmes A, Delahunt E. Treatment of common deficits associated with chronic ankle instability. Sports Medicine. 2009; 39(3):207-24. [DOI:10.2165/00007256-200939030-00003] [PMID]

[6] Powers CM. The influence of altered lower-extremity kinematics on patellofemoral joint dysfunction: A theoretical perspective. The Journal of Orthopaedic and Sports Physical Therapy. 2003; 33(11):639-46. [DOI:10.2519/jospt.2003.33.11.639] [PMID]

[7] Cote KP, Brunet ME, Gansneder BM, Shultz SJ. Effects of pronated and supinated foot postures on static and dynamic postural stability. Journal of Athletic Training. 2005; 40(1):41-6. [PMID] [PMCID]

[8] Sahrmann Sh. Movement system impairment syndromes of the extremities, cervical and thoracic spines. St. Louis: Mosby; 2011. https://books.google.com/books?id=hAZTVFiTUoC\&dq

[9] Bellchamber TL, van den Bogert AJ. Contributions of proximal and distal moments to axial tibial rotation during walking and runing. Journal of Biomechanics. 2000; 33(11):1397-403. [DOI:10.1016/S0021-9290(00)00113-5]

[10] Yalcin E, Kurtaran A, Selcuk B, Onder M, Yildirim MO, Akyuz M. Isokinetic measurements of ankle strength and proprioception in patients with flatfoot. Isokinetics and Exercise Science. 2012; 20(3):167-71. [DOI:10.3233/IES-2012-0453]

[11] Lephart SM, Pincivero DM, Giraldo JL, Fu FH. The role of proprioception in the management and rehabilitation of athletic injuries. The American Journal of Sports Medicine. 1997; 25(1):130-7. [DOI:10.1177/036354659702500126] [PMID]

[12] Khayambashi Kh, Mohammadkhani Z, Ghaznavi K, Lyle MA, Powers CM. The effects of isolated hip abductor and external rotator muscle strengthening on pain, health status, and hip strength in females with patellofemoral pain: A randomized controlled trial. The Journal of Orthopaedic and Sports Physical Therapy. 2012; 42(1):22-9. [DOI:10.2519/ jospt.2012.3704] [PMID]

[13] Synder KR, Earl JE, O'Connor KM, Ebersole KT. Resisrance training is accompanied by increases in hip strength and changes in lower extremity biomechanics during runing. Clinical Biomechanics. 2009; 24(1):26-34. [DOI:10.1016/j.clinn biomech.2008.09.009] [PMID]

[14] Dadashpoor A, Shojaeddin SS, Alizadeh MH. [The effect of strength exercise program on the hip abductor and lateral rotator muscles in correcting pronated foot (Persian)]. Journal of Rafsanjan University of Medical Sciences. 2014; 12(11):881-94. http://journal.rums.ac.ir/article-1-1499-en.html

[15] Farokhmanesh Kh, Ghasemi MS, Saeedi H, Roudbari M, Emadifar R. [Effect of foot hyperpronation on spine alignment, in standing position (Persian)]. Journal of Modern Rehabilitation. 2012; 6(2):65-70. http://mrj.tums.ac.ir/article-1-40-fa. html

[16] Nejati P, Forugh B, Kuhpayezade J, Moeineddin R, Nejati M. [Effects of foot orthoses on knee pain and function of female athletes with patellofemoral pain syndrome (Persian)]. Journal of Advances in Medical and Biomedical Research. 2009; 17(66):49-60. http://zums.ac.ir/journal/article-1-908-en.html 
[17] Holmes CF, Wilcox D, Fletcher JP. Effect of modified, low- dye medial longitudinal arch taping procedure on the subtalar joint neutral position before and after light exercise. The Journal of Orthopaedic and Sports Physical Therapy. 2002; 32(5):194-201. [DOI:10.2519/jospt.2002.32.5.194] [PMID]

[18] Feltner ME, Macrae HSH, Macrae PG, Turner NS, Hartman CA, Summers ML, et al. Strength training effects on rearfoot motion in running. Medicine and Science in Sports and Exercise. 1994; 26(8):1021-7. [DOI:10.1249/00005768-199408000-00014]

[19] Tsai LC, Yu B, Mercer VS, Gross MT. Comparison of different structural foot types for measures of standing postural control. The Journal of Orthopaedic and Sports Physical Therapy. 2006; 36(12):942-53. [DOI:10.2519/jospt.2006.2336] [PMID]

[20] Herrington L, Hatcher J, Hatcher A, McNicholas M. A comparison of star excursion balance test reach distances between ACL deficient patients and asymptomatic controls. The Knee. 2009; 16(2):149-52. [DOI:10.1016/j.knee.2008.10.004] [PMID]

[21] Chougala A, Phanse V, Khanna E, Panda S. Screening of body mass index and functional flatfoot in adult: An observational study. International Journal of Physiotherapy and Research. 2015; 3(3):1037-41. [DOI:10.16965/ijpr.2015.133]

[22] Culik J, Marik I, Cerny EP. Biomechanics of leg deformity treatment. Journal of Musculoskeletal \& Neuronal Interactions. 2008; 8(1):58-63. [PMID]

[23] Youdas JW, Hollman JH, Krause DA. The effects of gender age, and body mass index on standing lumbar curvature in persons without current low back pain. Physiotherapy Theory and Practice. 2006; 22(5):229-37. [DOI:10.1080/09593980600927864] [PMID]

[24] Seidi F, Rajabi R, Ebrahimi TI, Tavanai AR, Moussavi SJ. The Iranian flexible ruler reliability and validity in lumbar lordosis measurements. World Journal of Sport Sciences. 2009; 2(2):95-9. https://www.researchgate.net/publication/256417662

[25] Padua DA, Marshall SW, Boling MC, Thigpen CA, Garrett WE, Beutler AI. The Landing Error Scoring System (LESS) is a valid and reliable clinical assessment tool of jump-landing biomechanics the JUMP-ACL study. The American Journal of Sports Medicine. 2009; 37(10):1996-2002 [DOI:10.1177/0363546509343200] [PMID]

[26] Dokht Fariba AA, Ghanizade Hesar N. [Effect of NASM corrective exercise on functional tests and Foot posture index (FPI) in children with flat foot (Persian)]. Paper presented at: $9^{\text {th }}$ International Congress on Phsycal Education and Sport Sciences. Urmia University; 9-10 March 2016; Urumia, Iran. https://www.sid.ir/fa/seminar/ViewPaper.aspx?ID=27138

[27] Goss K. The ultimate guide to Fixing Flat Feet [Internet]. 2018 [Updated 2018 Oct 16]. Available from: https://www. healthline.com/health/flat-feet-exercises

[28] Cook G, Burton L, Hoogenboom B. Pre-participation screening: The use of fundamental movements as an assessment of function - part 1. North American Journal of Sports Physical Therapy. 2006; 1(2):62-72. [PMID] [PMCID]

[29] Sorenson EA. Functional movement screen as a predictor of injury in high school basketball atheletes [PhD. dissertation]. Eugene, OR: University of Oregon; 2009. https://scholarss bank.uoregon.edu/xmlui/handle/1794/10594

[30] Teyhen DS, Shaffer SW, Lorenson CL, Halfpap JP, Donofry DF, Walker MJ, et al. The functional movement screen: A reli- ability study. The Journal of Orthopaedic and Sports Physical Therapy. 2012; 42(6):530-40. [DOI:10.2519/jospt.2012.3838] [PMID]

[31] Chorba RS, Chorba DJ, Bouillon LE, Overmyer CA, Landis JA. Use of a functional movement screening tool to determine injury risk in female collegiate athletes. North American Journal of Sports Physical Therapy. 2010; 5(2):47-54. [PMID] [PMCID]

[32] Shojaedin SS, Hadadnezhad M. [Relationship between Functional Movement Screen (FMS) score and the history of injury and identify the predictive value of the FMS (Persian)]. Journal of Research in Rehabilitation Sciences. 2013; 9(3):459-69. http://jrrs.mui.ac.ir/index.php/jrrs/article/view/967

[33] Hertel J, Dorfman JH, Braham RA. Lower extremity malalignments and anterior cruciate ligament injury history. Journal of Sports Science \& Medicine. 2004; 3(4):220-5. [PMID] [PMCID]

[34] Daneshmandi H, Alizadeh MH, Gharakhanlou R. [Corrective exercises (Persian)]. Tehran: Samt; 2005. p. 87-117. http:// opac.nlai.ir/opac-prod/bibliographic/721627

[35] Devita P, Skelly WA. Effect of landing stiffness on joint kinetics and energetics in the lower extremity. Medicine \& Science in Sports \& Exercise. 1992; 24(1):108-15. [DOI:10.1249/00005768199201000-00018]

[36] Beutler A, de la MotteS, Marshall S, Padua D, Boden B. Muscle strength and qualitative jump-landing differences in male and female military cadets: The JUMP-ACL study. Journal of Sports Science \& Medicine. 2009; 8(4):663-71. [PMID] [PMCID]

[37] Saidi F, Rajabi R, Ebrahimi Takamejani E, Mosavi SJ. [Reliability and validity of Iranian flexible ruler in lumbar spine curvature measurement (Persian)]. Journal of Movement Science \& Sports. 2009; 7(14):31-8. https://www.sid.ir/fa/journal/ViewPaper.aspx?ID=156097

[38] Rajabi R, Latifi S. [Criterion curvature of the back spine (kyphosis) and lumbar (lordosis) of Iranian men and women (Persian)]. Research on Sport Sciences. 2010; 7:13-30. http:// ensani.ir/fa/article/309690/

[39] Lynn SK, Padilla RA, Tsang KKW. Differences in static- and dynamic-balance task performance after 4 weeks of intrinsicfoot-muscle training: The short-foot exercise versus the towelcurl exercise. Journal of Sport Rehabilitation. 2012; 21(4):327-33. [DOI:10.1123/jsr.21.4.327] [PMID]

[40] Sulowska I, Oleksy Ł, Mika A, Bylina D, Sołtan J. The influence of plantar short foot muscle exercises on foot posture and fundamental movement patterns in long-distance runners, a non-randomized, non-blinded clinical trial. PLoS One. 2016; 11(6):e0157917. [DOI:10.1371/journal.pone.0157917] [PMID] [PMCID]

[41] Goo YM, Kim TH, Lim JY. The effects of gluteus maximus and abductor hallucis strengthening exercises for four weeks on navicular drop and lower extremity muscle activity during gait with flatfoot. Journal of Physical Therapy Science. 2016; 28(3):911-5. [DOI:10.1589/jpts.28.911] [PMID] [PMCID]

[42] Mahdavi AR, Hadadnezhad M, Eftekhari F. [Effect of 6 week stretching training of Gastrocnemius-Soleus complex on dorsiflexion range of motion, ankle proprioception, knee valgus and function in athletes with limited dorsiflexion (Persian)]. Journal of Research in Sport Rehabilitation. 2018; 6(11):21-32 [DOI:10.22084/RSR.2018.14281.1337] 
[43] Najafi M, Shojaedin S, Haddadnejad M, Barati AH. [Effect of eight-week corrective exercises on the activity of involved muscles in ankle balance strategies in girls with lower limb pronation syndrome (Persian)]. The Scientific Journal of Rehabilitation Medicine. 2018; 7(1):77-87. [DOI:10.22037/ JRM.2018.110812.1546]

[44] Kouhi Achachlouei F, Abbaszadegan M, Eghbalmoghanlou A. The effects of corrective exercise program on flat foot deformity of male and female students. Annals of Biological Research. 2012; 3(2):988-94. https://www.scholarsresearchlibrary.com/articles/the-effects-of-corrective-exercise-programon-flat-foot-deformityof-male-and-female-students.pdf

[45] Lee JH, Cynn HS, Yoon TL, Choi SA, Kang TW. Differences in the angle of the medial longitudinal arch and muscle activity of the abductor hallucis and tibialis anterior during sitting short-foot exercises between subjects with pes planus and subjects with neutral foot. Journal of Back and Musculoskeletal Rehabilitation. 2016; 29(4):809-15. [DOI:10.3233/BMR160693] [PMID]

[46] Abdoli B, Teymoori M, Zamani Sani SH, Zeraatkar M, Hovanloo F. [Relationship between Plantar longitudinal arches and some selected motor parameters in children aging 11 to 14 years (Persian)]. Journal of Research in Rehabilitation Sciences. 2011; 7(3):381-90. http://jrrs.mui.ac.ir/index.php/jrrs/ article/view/209

[47] Nazari MH, Jamashidi AA, Peeri M, Sadeghi R, Mahmudi F. [Assessment of muscle strength imbalance of ankle, knee and hip joints as one of important biomechanical factors in predicting of extremity lower sport injuries among elite young athletes (Persian)]. Olympic. 2013; 20(4):99 -113. https://www.sid.ir/fa/journal/ViewPaper.aspx?ID=181453

[48] Shojaeddin SS, Sadeghi H, Torkamaani H. [The effect of six weeks strength training on eversion to inversion ratios in soccer players with chronic ankle instability (Persian)]. Journal of Movement Science \& Sports. 2008; 5(10):39-47. https:/ / www sid.ir/fa/journal/ViewPaper.aspx?ID=72431

[49] Willson JD, Dougherty CP, Ireland ML, Davis IM. Core stability and its relationship to lower extremity function and injury. Journal of the American Academy of Orthopaedic Surgeons. 2005; 13(5):316-25. [DOI:10.5435/00124635-200509000-00005] [PMID] 